\title{
sciendo

\section{Effects of Methyl Acetate as Oxygenated Fuel Blending on Performance and Emissions of SI Engine}

\author{
Abdulvahap CAKMAK ${ }^{1 *}$, Murat KAPUSUZ ${ }^{2}$, Orkhan GANIYEV ${ }^{3}$, Hakan OZCAN ${ }^{4}$ \\ ${ }^{1}$ Department of Motor Vehicles and Transportation Technologies, Samsun University, Samsun, Turkey \\ ${ }^{2,4}$ Department of Mechanical Engineering, Ondokuz Mayls University, Samsun, Turkey \\ ${ }^{3}$ UBOC Oil Company, Baku, Azerbaijan
}

\begin{abstract}
The objective of this paper is to investigate the use of methyl acetate as oxygenated fuel blending for base gasoline in SI engine. The effects of methyl acetate on engine performance parameters (brake specific fuel consumption, brake thermal efficiency and energy consumption rate) and exhaust emissions ( $\mathrm{CO}, \mathrm{HC}, \mathrm{CO}_{2}$ and $\mathrm{NO}_{\mathrm{x}}$ ) of SI engine have been experimentally investigated. Engine experiments were conducted on a single cylinder, water cooled, spark-ignition test engine at constant moderate speed; $1500 \mathrm{rpm}$ for different loads; 104, 207, 311 and $414 \mathrm{kPa}$ fuelling the engine with base gasoline, M5 (95 \% base gasoline $+5 \%$ methyl acetate) and M10 (90 \% base gasoline $+10 \%$ methyl acetate). The results showed that adding methyl acetate to base gasoline increases the brake specific fuel consumption while reducing the brake thermal efficiency of the engine. Furthermore, it was also observed that methyl acetate addition does not have a great effect on $\mathrm{HC}$ emissions, however, reduces $\mathrm{CO}$ and increases $\mathrm{CO}_{2}$ emissions. $\mathrm{NO}_{x}$ results showed a striking increase in the level of $\mathrm{NO}_{\mathrm{x}}$ emissions with the addition of methyl acetate.
\end{abstract}

Keywords - Gasoline; methyl acetate; oxygenated fuel; performance and emissions; SI engine

\begin{tabular}{lll} 
Nomenclature & & \\
CA & Crank Angle & Degree \\
TDC & Top Dead Center & \\
BMEP & Brake Mean Effective Pressure & $\mathrm{kPa}$ \\
BSFC & Brake Specific Fuel Consumption & $\mathrm{kg} / \mathrm{kgh}$ \\
SI & Spark Ignition & \\
\hline
\end{tabular}

\section{INTRODUCTION}

Due to the issues of the energy crisis, global warming, high fossil fuel cost and stringent emission regulations, more attention over the decades has been placed on renewable oxygenated fuels [1], [2]. Nevertheless, today oil-based fuels are the main source of global energy demand for the transport sector [3]. In order to reduce the use of fossil fuels and exhaust emissions, petroleum based fuels must be replaced or at least mixed at certain rates with renewable fuel [3], [4]. The benefits of renewable oxygenated fuels are the spread of low $\mathrm{CO}$, HC and PM emissions compared to gasoline that can be generated by domestic resources and reducing foreign energy dependence [5]. That is the reason why many countries

\footnotetext{
* Corresponding author.

E-mail address: a.cakmak.tr@gmail.com
} 
have to develop fuel regulation to increase the renewable oxygenated fuel content in fuels for transportation [5], [6].

As oxygenated fuels alcohols and ethers have been used to reduce exhaust emissions and increase the knock resistance of the fuel for a long time over the world. Among them, the most known and used is ethanol which can be produced by fermentation process from agricultural products or from the other feedstock such as waste from agricultural crops, food and beverage and municipal refuse [7]. Currently, ethanol is used as fuel in many countries especially in Brazil, Canada, USA, and India [1]. Moreover, in many other countries ethanol is blended with gasoline to increase knock resistance and improve fuel combustion. Apart from ethanol, alcohols such as methanol, butanol, and ethers like ETBE and MTBE are used as mixing oxygenated fuel with gasoline to increase oxygen content and octane number of the fuel. In this way, in the European Union and in the USA, oxygenated fuels are added to gasoline to get the ratio of $3.7 \mathrm{wt}$. \% oxygen [8], [9].

All oxygenated fuels have different physical and chemical fuel properties that affect certain key properties of blending fuel and have significant impact on the engine performance and emissions [1], [5]. The oxygen content of alcohols and ethers improves the combustion and reduces $\mathrm{CO}, \mathrm{HC}$ and $\mathrm{PM}$ emissions. They provide higher volumetric efficiency because of their higher heat of vaporization [1]. Thanks to their higher octane number, the knocking resistance of the blended fuel is higher.

Nevertheless, alcohols and ethers are not a problem-free fuel because of their negative impacts in terms of applicability. For example, alcohols increase the Reid vapor pressure of the gasoline-alcohol blends and this situation directly affects the evaporative HC emissions [10], [11]. Ethers such as MTBE have high solubility in water and may leak from storage tanks and contaminate groundwater [12]. The heating values of alcohols and ethers are lower than that of gasoline owing to structural oxygen content in the molecular structure. Furthermore, alcohols are not easily miscible with gasoline and at lower temperature phase separation could appear [13].

For all the above-mentioned reasons and since the use of alternative fuels in the future is inevitable [1], research on alternative oxygenated fuels could replace alcohol and ether fuels are ongoing with great interest.

Methyl acetate as a new oxygenated fuel has emerged as a potential alternative fuel compared to alcohols and ethers because of its advantages over them.

Methyl acetate also known as methyl ethanoate, is a carboxylate ester [14]. Its chemical formula is $\mathrm{C}_{3} \mathrm{H}_{6} \mathrm{O}_{2}$ and it can be produced from the liquid phase chemical reaction of methanol and acetic acid in the presence of an acid catalyst at atmospheric pressure [15]. Methyl acetate is also produced industrially by carbonylation of methanol as a by-product of the production of acetic acid [14].

The main advantage of methyl acetate is that it could be used as an octane booster and fuel extender without increasing the Reid vapor pressure of the methyl acetate-gasoline blends. It is nontoxic and produces less unregulated emissions. Low-cost production compared to ETBE and MTBE, lower volatility and easy handling is another advantage of the methyl acetate [14]. Additionally, methyl acetate is widely used as a solvent in many industries.

Since the methyl acetate could potentially replace alcohols and ethers as an oxygenated fuel and combustion enhancer, the purpose of this study is to experimentally investigate the usability of methyl acetate as oxygenated blending fuel in spark ignition engine in terms of distillation, engine performance and exhaust emission characteristics. 


\section{EXPERIMENTAL SECTION}

\subsection{Fuels}

To carry out this research, a commercial unleaded gasoline was used as reference fuel and purchased from a local petrol station. Methyl acetate was obtained in $99.5 \%$ purity from TEKKIM, a local chemical company. Firstly, unleaded gasoline $(G)$ was mixed with methyl acetate in a ratio of $5 \%$ by volume and $10 \%$ was named M5 and M10. Secondly, the lower heating value and density of the M5 and M10 fuels were determined in our laboratory by following the ASTM D 240 and ASTM D 4052 standards, respectively. The other physical and chemical fuel properties have been obtained from literature. Table 1 lists some important fuel properties for used fuels and methyl acetate. It is seen that the measured fuel properties of the test fuels are in compliance with EN 228 gasoline specifications.

Moreover, in this study, distillation curves of test fuels were investigated using LAB-KITS Distillation Tester (Model: PT-SYD-6536). The distillation curve is a significant feature that affects the engine performance and evaporative emissions of SI engine. Gasoline contains different hydrocarbons and each hydrocarbon molecule evaporates at a different temperature [16]. The light fractions ( $0 \%$ to $\sim 40 \%$ of evaporated volume) improve the cold start performance of the engine but high volatility is not desirable in all working conditions because it reduces the volumetric efficiency by replacing the air in cylinder and causes vapour lock in the fuel system [17]. The medium fraction ( $40 \%$ to $~ 80 \%)$ influences the engine warm-up, the vehicle acceleration performance and fuel economy. Lubrication oil dilution, formation carbon deposits and volatile organic compounds (VOC) depend on a heavy fraction ( $\sim 40 \%$ to $\sim 80 \%$ ) [5]. Figure 1 shows the distillation curves for gasoline, M5 and M10. When distillation curves of the test fuel are compared, there is found to be little difference between them. Distillation properties of all test fuels meet EN 228 specifications. However, the distillation temperature of M5 is slightly higher than that of M10 and gasoline. Additionally, it is noted that the distillation temperatures are not proportional to the volume of methyl acetate blended with gasoline. This could indicate that methyl acetate is solved in gasoline and new chemical bonds are formed [16]. The concentrations of methyl acetate up to $10 \%$ do not significantly affect the temperature-vaporization curve of the gasoline which makes it possible to use methyl acetate as blending fuel.

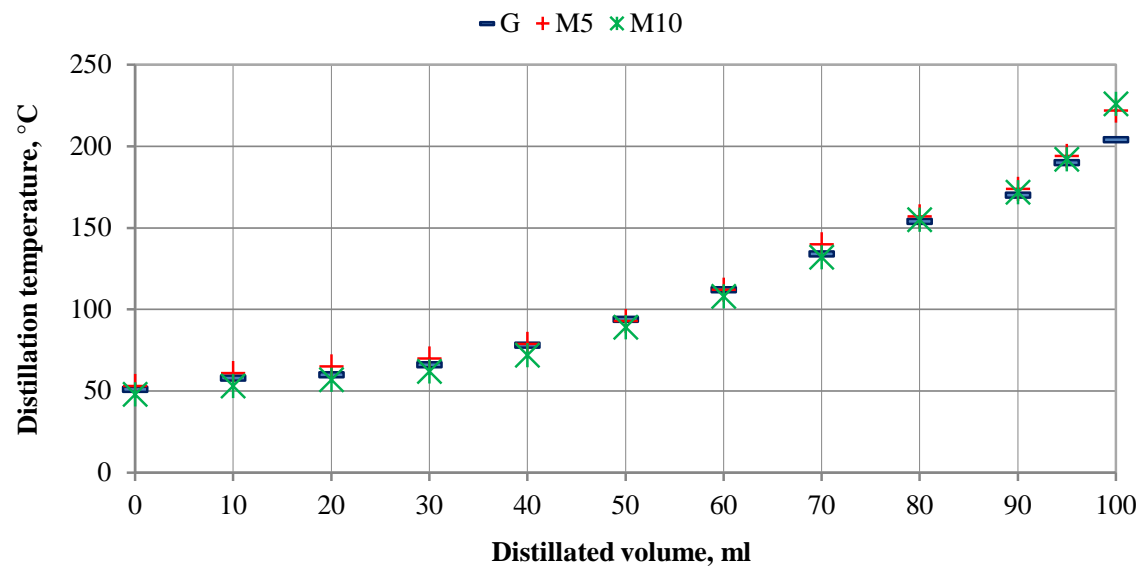

Fig. 1. Distillation curve for gasoline, M5, and M10. 
TABle 1. Fuel Properties for Test Fuels and Methyl ACetate [14], [17]-[19]

\begin{tabular}{lllll}
\hline Property & Gasoline & M5 & M10 & Methyl Acetate \\
\hline Chemical formula & - & & & $\mathrm{C}_{3} \mathrm{H}_{6} \mathrm{O}_{2}$ \\
Molecular mass, kg/kmol & $95-120$ & & & 74.08 \\
Oxygen Content, wt. \% & - & - & - & 43.20 \\
Density, kg/m ${ }^{3}$ & $720-760$ & 734 & 745 & 940 \\
Latent heat of vaporization at $20^{\circ} \mathrm{C}, \mathrm{kJ} / \mathrm{kg}$ & 307 & - & - & 410 \\
Stoichiometric air/fuel ratio (AFR) & 14.6 & - & - & 6.52 \\
Lower heating value, kJ/kg & 43000 & 41615 & 40270 & 21500 \\
Reid vapor pressure, $\mathrm{kPa}$ & $45-90$ & - & - & 41 \\
Research octane number & $95>$ & - & - & 110 \\
Motor octane number & $85>$ & - & - & - \\
\hline
\end{tabular}

\subsection{Experimental Facilities}

In this study, unleaded gasoline, M5, and M10 were tested in a single cylinder, water cooled, four stroke, and spark ignition research engine. The detailed characteristics of the test engine and the measurement system are listed in Table 2. The schematic view of experimental arrangement is given in Fig. 2. No modification was made on the test engine. The water-cooled Eddy current dynamometer was used to load the engine. Engine performance and emissions experiments were conducted at $1500 \mathrm{rpm}$ as medium speed and four loads (brake mean effective pressure) that are 104, 207, 311 and $414 \mathrm{kPa}$. In these test conditions, the throttle valve position was fixed to obtain the same brake power for each test fuel use. All tests were performed under constant spark timing (10 CA bTDC) and compression ratio (8:1). During the experiments, all data were taken after steady-state conditions were reached and all measurements were repeated at least three times at each test point and the average values were used to minimize the systematic error. Gas emissions such as carbon monoxide (CO), hydrocarbon (HC), carbon dioxide $\left(\mathrm{CO}_{2}\right)$ and nitrogen oxides $\left(\mathrm{NO}_{\mathrm{x}}\right)$ were measured using an exhaust gas analyzer. The measurement range and accuracy are given in Table 3.

TABle 2. The Detailed Characteristics of Test Engine And MEASUREMENT System

\begin{tabular}{ll}
\hline Type & Single cylinder, water cooled, four stroke \\
\hline Dimensions: bore/stroke, mm & $87.5 / 110$ \\
Compression ratio & 8, CR variation: 6:1-10:1 \\
Cylinder volume, cm ${ }^{3}$ & 661 \\
Maximum brake power & $4.5 \mathrm{~kW} @ 1800 \mathrm{rpm}$ \\
Spark timing & 10 CA bTDC, Spark variation: 0-70 CA bTDC \\
Dynamometer & Type: Eddy current, water cooled, with a loading unit \\
Speed, rpm & 1500 rpm, Speed range: 1200-1800 rpm \\
Air flow transmitter & Pressure Transmitter, Range (-) 250 mm WC \\
Fuel flow transmitter & DP transmitter, Range 0-500 mm WC \\
Crank angle sensor & Resolution 1 Degree, Speed 5500 rpm with TDC pulse \\
Piezo sensor & PCB Piezotronics; Combustion: Range 350 Bar \\
\hline
\end{tabular}




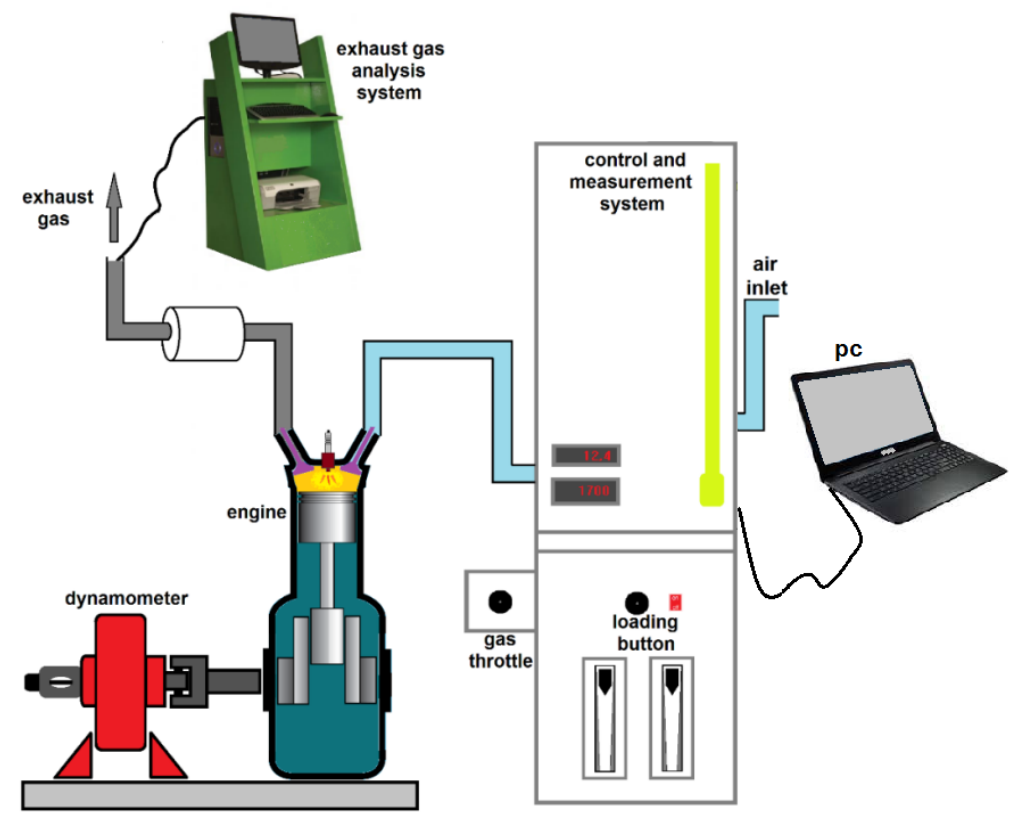

Fig. 2. Schematic view of the experimental arrangement.

TABle 3. MEAsurement RANGe AND ACCURACy of EXHAust Gas ANALYZER

\begin{tabular}{lll}
\hline Emissions & Measuring range & Accuracy \\
\hline $\mathrm{CO}$ & $0-10 \%$ vol. & $0.001 \%$ \\
$\mathrm{CO}_{2}$ & $0-20 \%$ vol. & $0.01 \%$ \\
$\mathrm{HC}$ & $0-4000 \mathrm{ppm}$ & $1 \mathrm{ppm}$ \\
$\mathrm{O}_{2}$ & $0-25 \%$ vol. & $0.01 \%$ \\
$\mathrm{NO}_{x}$ & $0-4000 \mathrm{ppm}$ & $1 \mathrm{ppm}$ \\
\hline
\end{tabular}

\subsection{Statistical (Uncertainty) Analysis}

In all experimental studies, physical quantities are measured with some errors and uncertainties. The errors and uncertainties can originate from the measurement device, calibration, test condition and procedure, observation and reading. In order to prove the accuracy of the measured and calculated data, an uncertainty analysis should be performed. The uncertainty analysis in this study was performed using the method proposed in [20].

$$
U_{\mathrm{R}}=\left[\left(\frac{\partial R}{\partial i_{1}} u_{1}\right)^{2}+\left(\frac{\partial R}{\partial i_{2}} u_{2}\right)^{2}+\left(\frac{\partial R}{\partial i_{3}} u_{3}\right)^{2}+\cdots+\left(\frac{\partial R}{\partial i_{\mathrm{n}}} u_{\mathrm{n}}\right)^{2}\right]^{1 / 2}
$$

where $U_{\mathrm{R}}$ is the total uncertainty of the calculated result of $R, i_{1}, i_{2}, i_{3}, \ldots, i_{\mathrm{n}}$ are independent variables, $u_{1}, u_{2}, u_{3}, \ldots, u_{n}$ are the uncertainties of each independent variables. 
The uncertainties of the calculated results and the measurement accuracies are given in Table 4.

TABle 4. MeAsured and CALCUlated UnCERTAinties in EXPERIMENTS

\begin{tabular}{ll}
\hline Measurements & Accuracy \\
\hline Brake torque, Nm & $\pm 1.5 \%$ \\
Engine speed, rpm & $\pm 0.06 \%$ \\
$\dot{\mathrm{m}}_{\text {air }}, \mathrm{kg} / \mathrm{h}$ & $\pm 0.2 \%$ \\
$\dot{\mathrm{m}}_{\text {fuel }}, \mathrm{cc} / \mathrm{min}$ & $\pm 0.25 \%$ \\
$\mathrm{P}_{\text {cyl }}, \mathrm{bar}$ & $\pm 0.2 \%$ \\
\hline Calculated parameters & Uncertainty \\
\hline Brake power, $\mathrm{kW}$ & $< \pm 1.5 \%$ \\
BSFC, gr $/ \mathrm{kWh}{ }^{-1}$ & $< \pm 1.52 \%$ \\
Brake thermal efficiency & $< \pm 1.6 \%$ \\
\hline
\end{tabular}

\section{RESUltS AND Discussion}

This section was divided into two parts such as; engine performance and exhaust emissions. In each section, the results of unleaded gasoline, M5 and M10 fuels were presented graphically and discussed in detail. Comparisons were made with the reference fuel unleaded gasoline. It is known that brake mean effective pressure (BMEP) does not depend on engine size and speed and thus it is widely used as performance parameter. Therefore, in this present study, the variation of the engine performance and exhaust emissions of test fuels were plotted corresponding to the same BMEP.

\subsection{Engine Performance}

Brake specific fuel consumption is a substantial engine performance parameter that gives the amount of consumed fuel to produce one effective power per hour. Fig. 3 shows the brake specific fuel consumption of the test engine versus BMEP for test fuels. As seen in this figure, due to its higher energy content, gasoline results in less brake specific fuel consumption than that of M5 and M10 at all loads. It is determined that by use of M5 and M10, the brake specific fuel consumption of the engine increased on average by $9.61 \%$ and $9.68 \%$, respectively. Because of the lower energy value and the higher density of the M5 and M10 compared to that of gasoline, much more fuel is consumed to obtain the same effective power. On the other hand, the curves of brake specific fuel consumption for the fuels show the same tendency. Due to the partial opening of the throttle valve, lower loads and thus lower volumetric efficiency result in an increase in the brake specific fuel consumption. However, at high loads pump losses are reduced by a larger opening of the throttle valve and this affects the engine performance positively. In addition, the cooling effect which is related to the latent heat of vaporization of the blend fuels has a great impact on volumetric efficiency at high loads [3]. At these points, the benefits of high volumetric efficiency are less fuel consumption and lower emissions. 


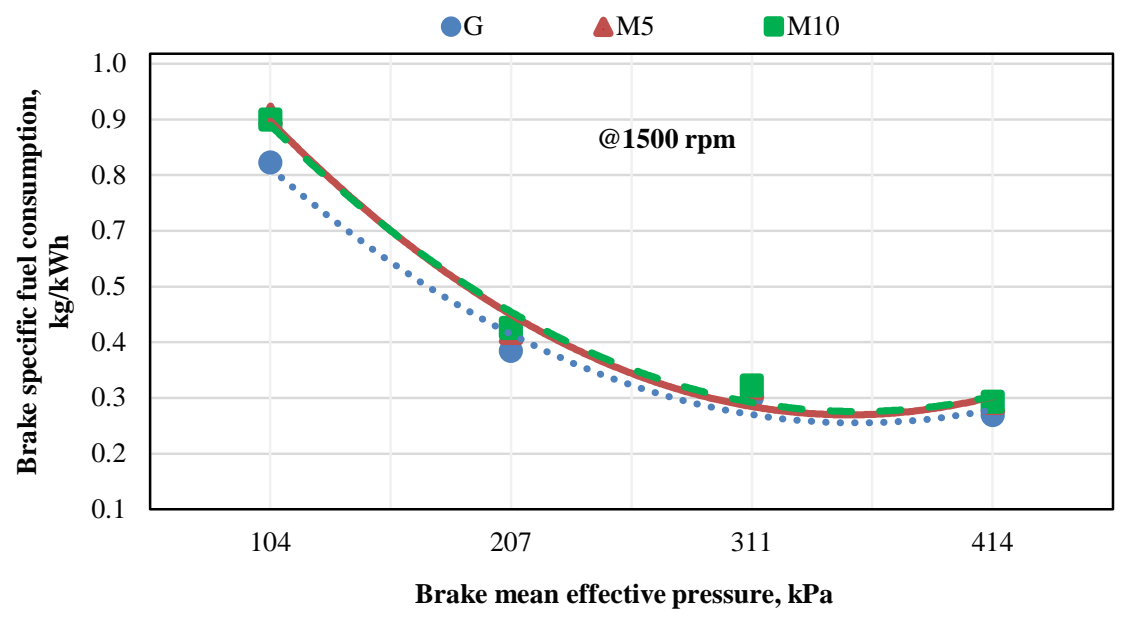

Fig. 3. Brake specific fuel consumption of the engine for tested fuels at different loads.

Since each fuel has different density and heating value, it is more meaningful to compare the fuels based on energy. For this purpose, the effect of test fuels on engine energy consumption per hour for the equal brake power was calculated and the results were showed graphically in Fig. 4. It is apparent from this figure that M5 results in more energy consumption than both gasoline and M10. With M5, the increment in energy consumption is calculated as $4.72 \%$ and $1.80 \%$ on average, compared to gasoline and M10. The increase in energy consumption depends on density, energy content and combustion performance of the fuel. In spite of the lowest energy content and the highest density of M10, it reduces the energy consumption as compared to M5. This is owing to the highest oxygen content of the M10 which enhances the combustion. This fact implies that engine runs more efficiently when using M10 than M5. This effect can also be clearly seen in Fig. 5. In order to enhance brake power by increasing the load at constant engine speed more fuel flow into the cylinder and this leads to an increase in energy consumption, naturally.

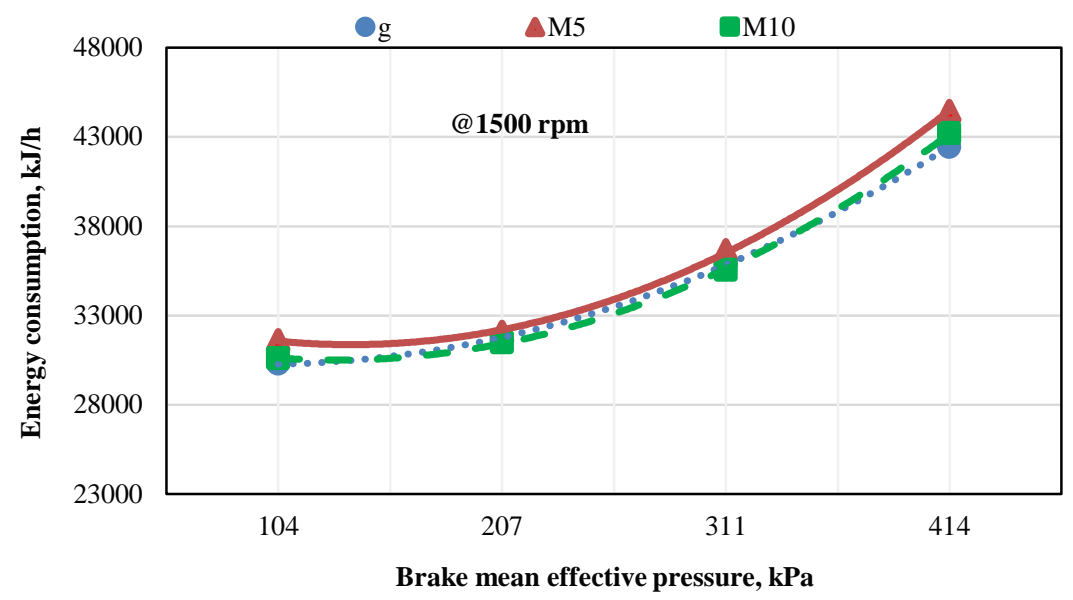

Fig. 4. Energy consumption per hour of the engine for tested fuels at different loads. 
The brake thermal efficiency of the engine at various loads for each fuel is compared in Fig. 5. This figure indicates the changes in brake thermal efficiency are similar but largely different, regardless of what type of fuel is used. Referring again in Fig. 5, it can be observed that the methyl acetate addition leads to a decrease in thermal efficiency during the entire load range due to the lower heating value of methyl acetate compared to gasoline. It was determined that average reduction in engine's thermal efficiency by fuelling the engine with M5 and M10 are $2.92 \%$ and $0.26 \%$, respectively when compared with gasoline. As stated above, the reason is the lower energy content of blended fuels. Nonetheless it is interesting that the reduction in brake thermal efficiency with use M5 is higher than M10. The main reason for this result may be the oxygen content of the fuel. The relative oxygen content in the fuel is an important factor affecting combustion efficiency [21]. Higher oxygen content in M10 enhances the completeness of combustion and this offers higher brake thermal efficiency. Moreover, it can be concluded that M10 is superior to M5 as a higher amount of renewable fuel will be used without a significant reduction in brake thermal efficiency.

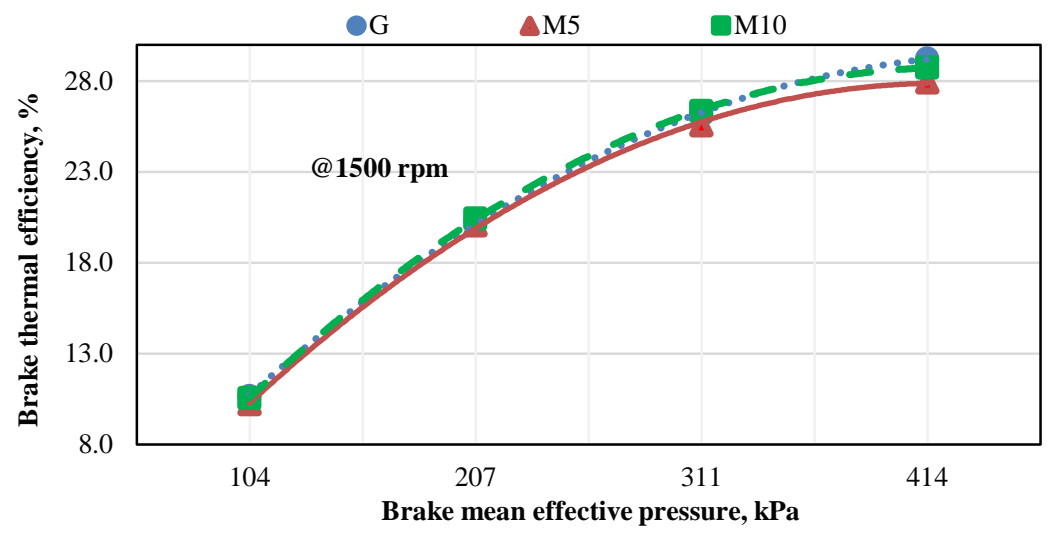

Fig. 5. Brake thermal efficiency of the engine for tested fuels at different loads.

\subsection{Exhaust Emissions}

CO emissions are essentially generated in an engine due to incomplete combustion. Incomplete combustion occurs because of poor air-fuel mixing, local rich mixture, low combustion temperature, and high carbon to hydrogen ratio of fuel [17], [22]. CO is an undesirable emissions and it represents the loss of fuel chemical energy. In Fig. 6 CO emissions are shown for test fuels. It can be noted an increase of $\mathrm{CO}$ emissions for all test fuels with load due to the rich mixture at high loads. There is a reduction in CO emissions especially at lower loads (104 and $207 \mathrm{kPa}$ ) for M5 and M10 due to oxygen content of the fuel that provides more oxidation of $\mathrm{CO}$ into $\mathrm{CO}_{2}$ [23]. The mean level of $\mathrm{CO}$ emissions for M5 and M10 are lower by $3.91 \%$ and $26.66 \%$ than that of the gasoline. However, when the engine was run on M5 at high loads CO emissions increased compared to gasoline and M10. The increment in CO emissions at high loads for the M5 can be explained by more fuel flowing into the cylinder to obtain the same brake power for M5 and M10 operation when compared to using gasoline. Due to high oxygen content in M10, the combustion is improved and therefore it causes a significant decrease in CO emissions especially at the lowest load by up to $90 \%$. That shows that M10 has better combustion ability than M5 and gasoline. 


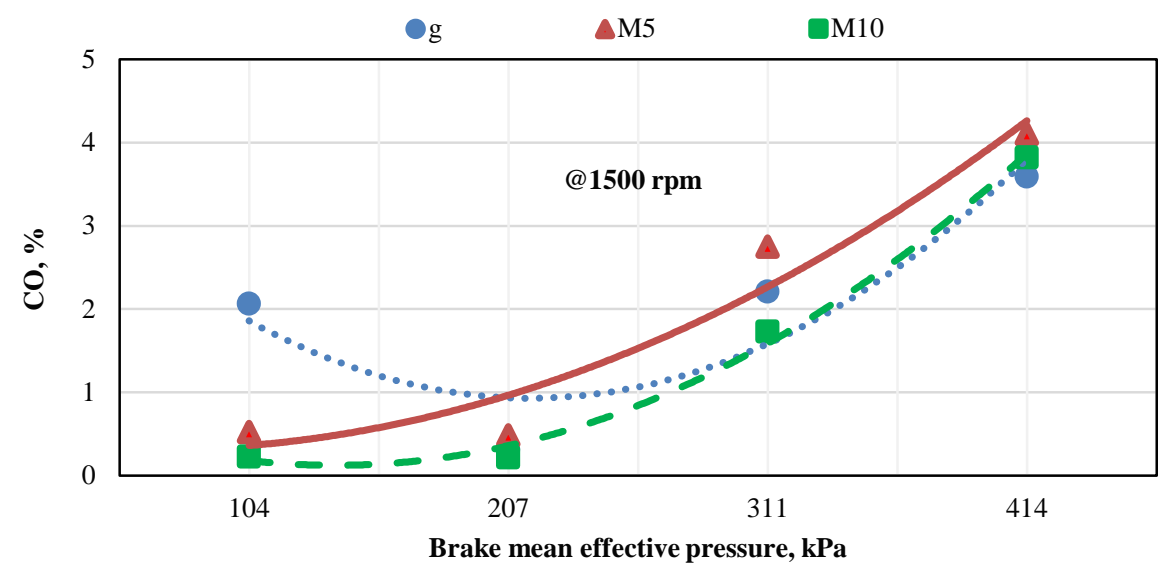

Fig. 6. CO emission for tested fuels at different loads.

Formation of HC emissions in internal combustion engines mainly depends on air-fuel ratio, fuel type, combustion chamber geometry, crevice volumes and operating parameters [17], [24]. HC emissions for M5, M10, and gasoline at various loads are illustrated in Fig. 7. It is noticeable that M5 and M10 blend fuels have advantages on HC emissions when compared with gasoline, at the lowest load. At the minimum load, M5 and M10 produce about $36.83 \%$ and $46.93 \%$ less HC emissions, respectively, than gasoline. This could be explained by the oxygen content of the blended fuels. However, at the other loads, HC emissions rise more rapidly with M5 and M10 compared to gasoline. This could be seen as evidence that substantial oxidation does not occur with the blended fuels at high loads. The oxidation rate of the fuel in the combustion chamber also depends on fuel-air ratio and combustion chamber temperature. It is determined that at maximum load, the fuel mass flow rate for M5 and M10 are $6.58 \%$ and $7.15 \%$ higher relative to gasoline, respectively. High fuel consumption could increase HC emissions for M5 and M10. In addition, reduction in cylinder temperature due to lower energy content and higher heat of vaporization for M5 and M10 can be another reason for high HC emissions. This phenomenon is supported by lower exhaust gas temperature of M5 and M10 than that of gasoline. But, when the average HC emissions are compared, there are no significant differences between test fuels.

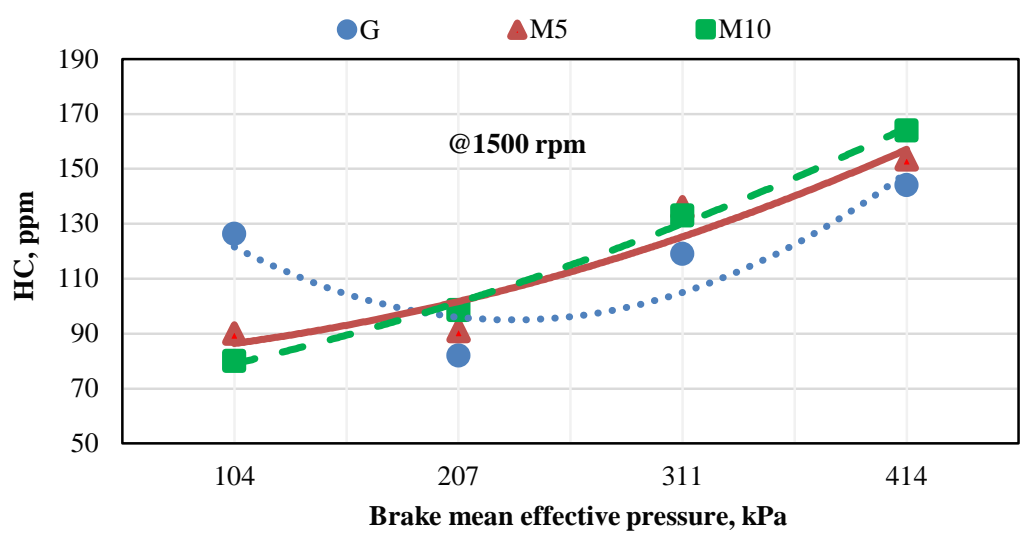

Fig. 7. HC emission for tested fuels at different loads. 
Carbon dioxide is a desirable combustion product in view of energy conversion since $\mathrm{CO}_{2}$ is produced by the complete burning of hydrocarbon fuel. Even though $\mathrm{CO}_{2}$ is not classified as an engine pollutant, it is the main greenhouse gas emission that leads to changes in the Earth's temperature [1]. Indeed, $\mathrm{CO}_{2}$ emissions in the internal combustion engines are heavily linked to the carbon-hydrogen ratio in fuel, and combustion temperature [25]. Fig. 8 presents the effect of the test fuels on $\mathrm{CO}_{2}$ emissions. As seen in this figure, within the entire load range M5 and M10 produce more $\mathrm{CO}_{2}$ emissions than gasoline. It is determined that $\mathrm{CO}_{2}$ emissions increased averagely by $14.87 \%$ and $19.89 \%$ with the use of M5 and M10, respectively. This result could be associated with oxygen content which plays the main role in increasing the completion of combustion, which increases the $\mathrm{CO}_{2}$ emission level [1], [26].

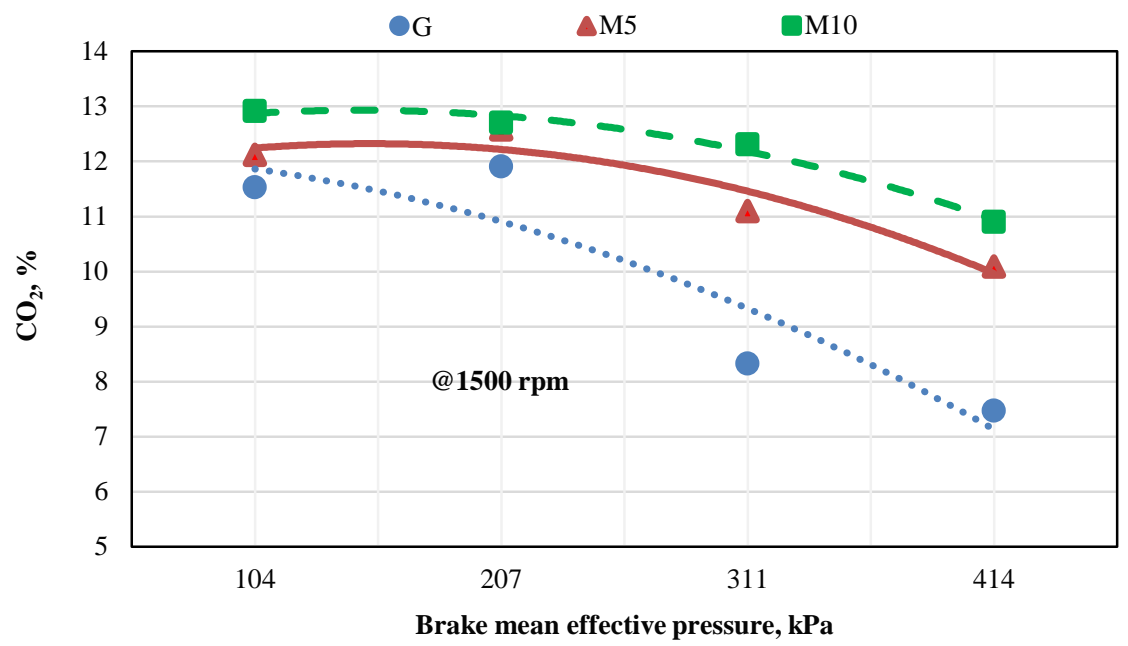

Fig. 8. $\mathrm{CO}_{2}$ emission for tested fuels at different loads.

The most important factors that affect $\mathrm{NO}_{\mathrm{x}}$ emissions are fuel-air ratio, combustion temperature and oxygen concentration in the combustion chamber [24]. Although, maximum combustion temperature occurs at slightly rich mixture $(\phi=1.1) \mathrm{NO}_{\mathrm{x}}$ emissions peak at slightly lean condition $(\phi=0.9)$ where the combustion temperature is high and there is high oxygen concentration [17], [24]. Thus it can be concluded that oxygen concentration is more dominant on $\mathrm{NO}_{\mathrm{x}}$ formation than cylinder temperature. It is seen in Fig. 9 that $\mathrm{NO}_{\mathrm{x}}$ emissions emitted by the M5 and M10 fuelled engine are significantly higher than that of gasoline at all loads. Higher oxygen concentration inside the combustion chamber with the use of M5 and M10 is the reason for high $\mathrm{NO}_{\mathrm{x}}$ emissions. Maximum $\mathrm{NO}_{\mathrm{x}}$ emissions were measured with M10 as 4798 ppm at a load of $207 \mathrm{kPa}$. The $\mathrm{NO}_{\mathrm{x}}$ emissions from M5 and gasoline at the same load are 4125 ppm and 3583 ppm, respectively. By taking into account all the load range $\mathrm{NO}_{\mathrm{x}}$ emissions of M10 and M5 are higher than that of gasoline by $78.40 \%$ and $34.85 \%$, respectively. Although this could be seen as a sign of improved combustion, the higher $\mathrm{NO}_{\mathrm{x}}$ emissions from M5 and M10 reduce the benefits of methyl acetate as oxygenated fuel. 


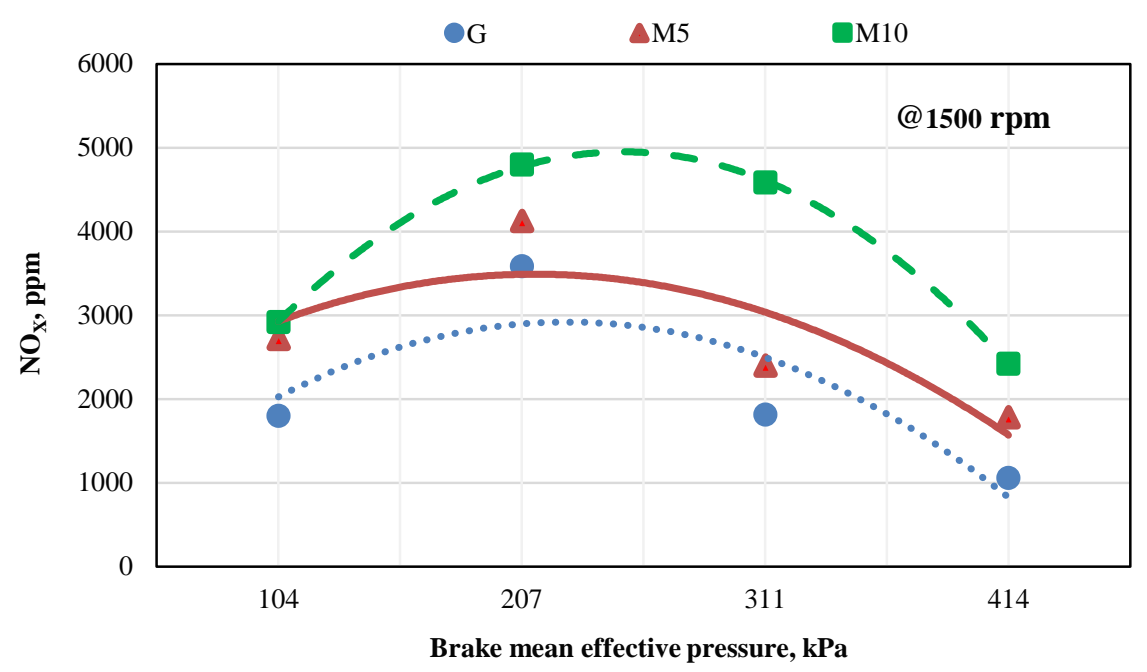

Fig. 9. $\mathrm{NO}_{\mathrm{x}}$ emission for tested fuels at different loads.

\section{Conclusions}

This experimental study presented the influence of the addition of methyl acetate as oxygenated fuel to unleaded gasoline on the performance and exhaust emissions of spark ignition engine. Engine experiments were conducted at the $1500 \mathrm{rpm}$ as medium speed of the test engine and four different loads. This results in the equal brake power for the test fuels at each test condition. Distillation curves of test fuels were also determined. It was observed that the distillation characteristics for test fuels were the same but slightly higher than the distillation temperature with M5. When the engine fuelled with M5 and M10 brake specific fuel consumption and energy consumption increased while brake thermal efficiency decreased due to lower heating value than gasoline. Regarding brake thermal efficiency, M10 presents higher values than M5 that which means that methyl acetate has a considerable advantage in this sense as gasoline substitute up to $10 \%$. In general, there is a slight decrease in $\mathrm{HC}$ and a significant decrease in CO observed when the use of M5 and M10 due to oxygen content. Within the entire load range methyl acetate-gasoline blends, produced more $\mathrm{CO}_{2}$ and $\mathrm{NO}_{\mathrm{x}}$ emissions than gasoline. It was also observed that in all operating conditions the higher percentage of methyl acetate in the blend, the greater $\mathrm{CO}_{2}$ and $\mathrm{NO}_{\mathrm{x}}$ emissions due to the highest oxygen content. When a general assessment is made it can be said that methyl acetate does not appear superior over alcohols and ethers in respect of engine performance and exhaust emissions. However, this finding bases on limited experimental data and thus the usability of methyl acetate as oxygenated fuel blending in spark ignition engine requires further investigation. For future studies, the compression ratio, the blending ratio and, spark timing may be optimized to increase the engine performance and to achieve further reduction in exhaust emissions. 


\section{REFERENCES}

[1] Awad O. I., Mamat R., Ali O. M., Sidik N. A. C., Yusaf T., Kadirgama K., Kettner M. Alcohol and ether as alternative fuels in spark ignition engine: A review. Renew. Sustain. Energy Rev. 2017:82:2586-2605. doi:10.1016/j.rser.2017.09.074

[2] Gulum M., Bilgin A. A comprehensive study on measurement and prediction of viscosity of biodiesel-diesel-alcohol ternary blends. Energy 2018:148:341-361. doi:10.1016/j.energy.2018.01.123

[3] Schifter I., Gonzalez U. Effects of ethanol, ethyl- tert -butyl ether and dimethyl-carbonate blends with gasoline on SI engine. Fuel 2016:183:253-261. doi:10.1016/j.fuel.2016.06.051

[4] Gulum M., Bilgin A., Cakmak A. Comparison of Opiımum Reaction Parameters of Corn Oil Biodiesels Produced by Using Sodium Hydroxide $(\mathrm{NaOH})$ and Potassium Hydroxide (KOH). J. Fac. Eng. Archit. Gazi Univ. 2015:30(3):503-511.

[5] Rodriguez-Anton L. M., Gutierrez-Martin F., Martinez-Arevalo C. Experimental determination of some physical properties of gasoline, ethanol and ETBE ternary blends. Fuel 2015:156:81-86. doi:10.1016/j.fuel.2015.04.040

[6] Rodriguez-Anton L. M., F. Gutierrez-Martin F., Doce Y. Physical properties of gasoline, isobutanol and ETBE binary blends in comparison with gasoline ethanol blends. Fuel 2016:166:73-78. doi:10.1016/j.fuel.2015.10.106

[7] Mccormick R. L., Parish R. Advanced Petroleum Based Fuels Program and Renewable Diesel Program. Milestone Report: Technical Barriers to the Use of Ethanol in Diesel Fuel. National Renewable Energy Laboratory, 2001.

[8] European Union. Directive 2009/28/EC of the European Parliament and of the Council. Off. J. Eur. Union 2009:140:16-62.

[9] European Union. Directive 2009/30/EC of the European Parliament and of the Council. Official Journal of the European Union 2009:140:88-133.

[10] Da Silva R., Cataluna R., De Menezes E. W., Samios D., Piatnicki C. M. S. Effect of additives on the antiknock properties and Reid vapor pressure of gasoline. Fuel 2005:84(7-8):951-959. doi:10.1016/j.fuel.2005.01.008

[11] Muzikova Z., Pospisil M., Sebor G. Volatility and phase stability of petrol blends with ethanol. Fuel 2009:88(8):1351-1356. doi:10.1016/j.fuel.2009.02.003

[12] Lince D. P., Wilson L. R., Carlson G. A. Methyl tert -Butyl Ether (MTBE) Contamination in Private Wells near Gasoline Stations in Upstate New York. Bulletin of Environmental Contamination and Toxicology 1998:61(4):484488, 1998. doi:10.1007/s001289900788

[13] Surisetty V. R., Dalai A. K., Kozinski J. Alcohols as alternative fuels: An overview. Appl. Catal. A Gen. 2011:404:(12):1-11. doi:10.1016/j.apcata.2011.07.021

[14] Dabbagh H. A., Ghobadi F., Ehsani M. R., Moradmand M. The influence of ester additives on the properties of gasoline. Fuel 2013:104:216-223. doi:10.1016/j.fuel.2012.09.056

[15] Huss R. S., Chen F., Malone M. F., Doherty M. F. Reactive distillation for methyl acetate production. Computers \& Chemical Engineering 2003:27:1855-1866. doi:10.1016/S0098-1354(03)00156-X

[16] Yumrutas R., Hakki M., Hakan O. Investigation of purified sulfate turpentine on engine performance and exhaust emission. Fuel 2008:87:252-259. doi:10.1016/j.fuel.2007.04.019

[17] Pulkrabek W. W. Engineering Fundamentals of the Internal Combustion Engine. Pearson New International Edition. Pearson Higher Ed., 2013.

[18] Necati A., Canakci M. Performance and combustion characteristics of alcohol-gasoline blends at wide-open throttle. Energy 2011:36(5):2747-2752. doi:10.1016/j.energy.2011.02.014

[19] Sufllta J. M., Mormlle M. R. Anaerobic Biodegradation of Known and Potential Gasoline Oxygenates in the terrestrial subsurface. Environmental Science \& Technology 1993:20:976-978. doi:10.1021/es00042a022

[20] Holman W. J., Gajda J. P. Experimental methods for engineers. New York: McGraw-Hill, 2001.

[21] Wang C., Xu H., Daniel R., Ghafourian A., Martin J. Combustion characteristics and emissions of 2-methylfuran compared to 2, 5-dimethylfuran, gasoline and ethanol in a DISI engine Combustion Duration n Duration. Fuel 2013:103:200-211. doi:10.1016/j.fuel.2012.05.043

[22] Pourkhesalian A. M., Shamekhi A. H., Salimi F. Alternative fuel and gasoline in an SI engine: A comparative study of performance and emissions characteristics. Fuel 2010:89(5):1056-1063. doi:10.1016/j.fuel.2009.11.025

[23] Cordeiro T. C., Melo D., Machado G. B., Belchior C. R. P., Colaco M. J., Barros J. E. M., De Oliveira E. J., De Oliveira D. G. Hydrous ethanol - gasoline blends - Combustion and emission investigations on a Flex-Fuel engine. Fuel 2012:97:796-804. doi:10.1016/j.fuel.2012.03.018

[24] Heywood J. B. Internal combustion engine fundamentals. McGraw-Hill Education, 1988.

[25] Awad O. I., Mamat R., Noor M. M., Ibrahim T. K., Yusri I. M., Yusop A. F. The impacts of compression ratio on the performance and emissions of ice powered by oxygenated fuels: A review. J. Energy Inst. 2018:91:19-32. doi:10.1016/j.joei.2016.09.003

[26] Wei H., Feng D., Shu G., Pan M., Guo Y., Gao D., Li W. Experimental investigation on the combustion and emissions characteristics of 2-methylfuran gasoline blend fuel in spark-ignition engine. Appl. Energy 2014:132:317-324. doi:10.1016/j.apenergy.2014.07.009 


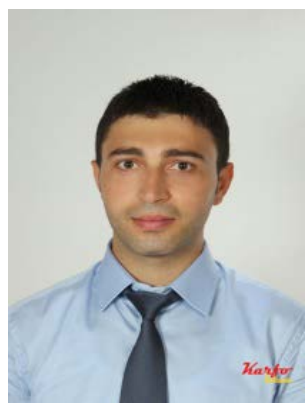

Abdulvahap Cakmak received his first BSc in Technical Education Faculty, Department of Automotive Education from the Dicle University, in 2010 and the second BSc in Mechanical Engineering from Karadeniz Technical University, Turkey. He obtained his Master's thesis in Mechanical Engineering (Automotive Science) from Karadeniz Technical University, in 2014. He is currently a PhD candidate in Mechanical Engineering at Ondokuz Mayıs University.

He is working as a Lecturer at Department of Motor Vehicles and Transportation Technologies in Samsun University. He is presently pursuing his $\mathrm{PhD}$ and his thesis is on the experimentally optimization of performance, combustion and emissions characteristics of a diesel engine using different techniques and additives. His research topics are internal combustion engine, energy and exergy analysis, fuels and combustion. Some of his previous publications are listed below:

[1] Behcet R., Oktay H., Cakmak A., Aydin H. Comparison of exhaust emissions of biodieseldiesel fuel blends produced from animal fats. Renewable and Sustainable Energy Reviews 2015:46:157-165.

[2] Cakmak A., Bilgin A. Exergy and energy analysis with economic aspects of a diesel engine running on biodiesel-diesel fuel blends. International Journal of Exergy 2017:24(2-4):151-172.

[3] Gulum M., Bilgin A., Cakmak A. Comparison of optimum reaction parameters of corn oil biodiesels produced by using sodium hydroxide $(\mathrm{NaOH})$ and potassium hydroxide $(\mathrm{KOH})$. Journal of the Faculty of Engineering and Architecture of Gazi University 2015:30(3):503-511.

ORCID iD: https://orcid.org/0000-0003-1434-6697
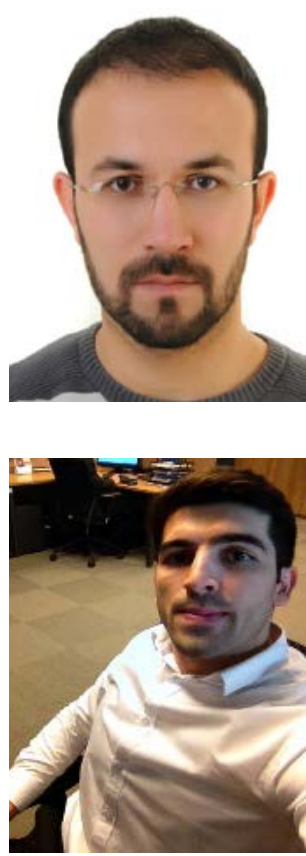

Murat Kapusuz graduated of Mechanical Engineering from the Harran University, in 2009. He received his MS degree in from Ondokuz May1s University in 2012. He is currently a PhD candidate in Mechanical Engineering at Ondokuz Mayıs University.

Orkhan Ganiyev graduated from the Mechatronics Engineer at the Azerbaijan State Oil Academy in 2014 his thesis was about artificial intelligence theory about automotive. In the same year applied for a master's degree in Turkey at the Ondokuz Mayıs University. Right now he has been researching his thesis about effects of methyl acetate and ethyl acetate fuel blending with gasoline on Performance and Emissions of SI Engine.

Orkhan is working mechanical engineer at the UBOC oil company. 


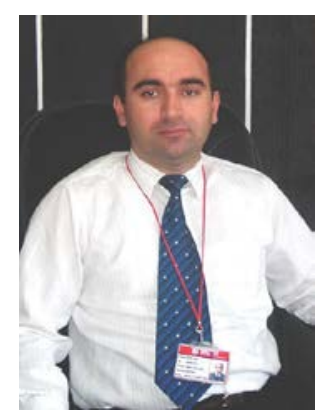

Hakan Ozcan is an Associate Professor in Mechanical Engineering Department. He received his BSc, MS degree and $\mathrm{PhD}$ in mechanical Engineering from the Gaziantep University, in 1995, 1997, 2005, respectively. His research interests are internal combustion engine, thermodynamic, alternative fuel, fuels and combustion. He has served as researcher and executive in many scientific research projects. He published more than fifteen scientific articles and conference papers until today.

ORCID iD: https://orcid.org/0000-0002-7848-3650 